\title{
ESTE MUNDO DE MISÉRIA E SOL: A NARRATIVA AUTOBIOGRÁFICA E A RElaÇÃo COM O REAl NA OBRA de Albert CAMUS
}

\author{
Samara Fernanda Almeida Oliveira de Lócio e Silva Geske ${ }^{1}$
}

RESUMO: A partir de uma análise do romance inacabado Le Premier Homme, este artigo pretende discutir a relevância da narrativa de cunho autobiográfico na obra de Camus e as tensões que o real cria com o ficcional. No romance, as lembranças de infância são o ponto de partida para a autobiografia ao mesmo tempo em que se coloca a serviço de uma estética: este mundo de miséria e sol torna-se agora o mundo da criação.

PALAVRAS-CHAVE: Albert Camus; Le Premier Homme; Autobiografia; Real.

ABSTRACT: Since the analysis the unfinished novel Le Premier Homme, this article intends to discuss the relevance of the autobiography narrative in the work of Camus and the tensions caused by the real with the fictional. In the novel, the childhood remembrances are the start point to the autobiography and at same time, it serves to the aesthetics of the narrative: this world of miseries and the sun turns the world of creation.

KEYWORDS: Albert Camus; Le Premier Homme; Autobiography; Real.

"La pauvreté, d'abord, n’a jamais été un malheur pour moi: la lumière y répandait ses richesses.”

Albert Camus

\section{Introdução}

No dia 4 de janeiro de 1960 morria em um acidente o escritor franco-argelino Albert Camus ${ }^{2}$. Passados cinquenta anos, leitores e críticos tem se lançado não só em busca da compreensão de sua obra, mas também sobre o homem. É o que demonstram os principais livros lançados esse ano na França em virtude do aniversário de sua morte, entre os quais podemos destacar Albert Camus: solitaire, solidaire, um álbum de fotos e lembranças organizado pela filha do autor, Catherine Camus.

Entre os objetos que restaram daquele acidente, uma maleta e nela alguns livros, fotos e um caderno contendo um manuscrito de 144 páginas para o qual o escritor já havia encontrado um título: Le Premier Homme. Diante de uma morte tão absurda, esse será um pequeno legado de Albert Camus a seus admiradores, que permitirá ao mesmo tempo uma reflexão sobre sua obra e sobre o homem que ele foi.

\footnotetext{
${ }^{1}$ Mestranda do Programa de Língua e Literatura Francesa (FFLCH-USP) pesquisando o processo de criação de L'étranger de Albert Camus.

2 A transcrição de um jornal da época nos dá a notícia: “C'est sur la R.N.5, entre Champigny-sur-Yonne et Villeneuve-la-Guyard (Yonne), à $1 \mathrm{~km}$ de cette localité et à hauteur du village de Villeblevin, que s'est produit, vers $14 \mathrm{~h}$. 15, l'accident au cours duquel l'écrivain a trouvé la mort. A la suite de l'éclatement d'un pneu, la puissante voiture (Facel Vega) que conduisait M. Michel Gallimard, 43 ans, et qui roulait à très vive al1ure en direction de Paris, s'est littéralement encastrée dans un platane. Albert Camus, qui était assis à côté du conducteur, fut tué sur le coup. M. Michel Gallimard, grièvement blessé, a été transporté immédiatement à l'hôpital de Montereau, ainsi que sa femme Jeanne, 40 ans, qui est grièvement atteinte, et leur fille Annie, 18 ans, qui, sous le choc, avait été projetée à une vingtaine de mètres dans un champ labouré et qui n'est que contusionnée. L'accident s'est produit en pleine ligne droite. La voiture a été complètement détruite”(1960).
} 
O manuscrito de Le Premier Homme, ao que tudo indica, parece ter sido escrito de uma só vez, pois não contém muitas rasuras nem variantes. Segundo Francine e Catherine Camus, que datilografaram o texto, ele comporta diversas dificuldades como parágrafos muito longos e uma pontuação confusa, isso se deveria em parte ao caráter inacabado do texto.

Através dos Carnets, pequenos cadernos em que o escritor fazia anotações, podemos encontrar numerosas notas para Le Premier Homme. A primeira delas é de 1940 (CAMUS, 1962, p. 210), neste ano o personagem principal já é designado por um “J.C.” , ou seja, Jacques Cormery. As notas do ano de 1942 (CAMUS, 1981, p. 973) têm como início a designação "Enfance pauvre”, já denotando um possível aspecto autobiográfico do texto. Essa ideia é derrubada por uma nota de 1946 (CAMUS, 1981, p. 1069): "Roman. Enfance pauvre.", e pelas notas seguintes que passam a denominar a narrativa como um romance.

Uma nota de 1953 (CAMUS, 1981, p. 100-101) prevê ainda outras duas partes que Camus não pôde terminar, que tratariam possivelmente da adolescência e a idade madura do herói. A narrativa encerra-se na infância de Jacques Cormery e seu primeiro beijo. De fato, o manuscrito possui uma temporalidade complexa, dando saltos entre o presente e o passado: a narrativa se inicia antes do nascimento do herói; adiante, o personagem ora nos narra no ano de 1953 quando tem 40 anos, ora aparece em sua infância.

Como podemos ver, existe uma dificuldade em classificar essa narrativa: trata-se de um romance ou uma autobiografia? Essa dificuldade nasce em primeiro lugar pelo fato de ser um manuscrito inacabado e não ter sido publicado em vida por seu autor. Podemos nos perguntar se as questões levantadas quanto à classificação do texto seriam as mesmas se Camus tivesse fechado e publicado sua história.

\section{Entre o real e a ficção}

Camus sempre considerou seu texto como um romance, e de fato este possui marcas que definiriam o gênero: é narrado em terceira pessoa, ou seja, não existe uma correspondência entre o nome do autor e do personagem; a narrativa inicia-se antes do nascimento do herói, o que impediria que fosse fruto de sua memória, ao contrário, é fruto de sua imaginação, e, portanto, ficcional e finalmente a narrativa não possui um pacto autobiográfico.

No entanto, segundo a discussão proposta por Philippe Lejeune, Le Premier Homme poderia ser considerado um romance autobiográfico. Trata-se de um texto de ficção onde o leitor tem razões para suspeitar, a partir das semelhanças que ele observa, que existe uma ligação entre a identidade do autor e do personagem, ainda que o autor tenha escolhido apagar essa identidade ou ao menos não afirmá-la.

\footnotetext{
${ }^{3}$ É interessante notar o quanto todos os escritos de Camus estão permeados de referências cristãs, seja através dos inúmeros padres que aparecem em suas histórias, seja através dos títulos e dos nomes dos personagens: La Chute - uma clara referência a queda bíblica, ao pecado e a culpa universal - e seu personagem Jean Baptiste, um juizpenitente; Le Premier Homme - uma referência a Adão, o primeiro homem e também ao segundo Adão, Jesus Cristo - vide a abreviação do nome do personagem (J.C.) e uma narrativa de seu nascimento que muito se assemelha a natividade bíblica.
} 
Existem diversas evidências que apontam para o aspecto autobiográfico da narrativa; a primeira delas se encontra na capa da edição da coleção folio da Gallimard: uma foto onde o jovem Albert se encontra entre seus colegas do time do Racing universitário. A edição coloca em destaque a figura de Camus esmaecendo a imagem dos colegas ao fundo, onde podemos ler que Camus seria o primeiro homem do time, isto é, o goleiro.

Virando as primeiras páginas encontramos uma dedicatória para a mãe de Camus "Intercesseur: Vve Camus, à toi qui ne pourras jamais lire ce livre”, que como a viúva Cormery também era analfabeta. A relação entre estas duas viúvas fica mais clara quando em uma passagem do texto o escritor, substitui a Vve Cormery ficcional pelo nome de sua mãe. Esse sobrenome que parece ter sido inventado ainda tem relação com a família de Camus: Cormery é o sobrenome de solteira de sua avó paterna.

O nome de M. Bernard também é substituído no texto pelo nome do professor de infância de Camus, M. Germain. Neste ponto, assim como no caso da capa, encontramos mais uma intervenção do editor. Ele anexa no final do texto duas cartas: uma de Camus a seu mestre M. Germain e sua resposta, deixando, dessa forma, explícita a equivalência entre a ficção e a biografia do escritor. Esse professor ocupa um papel fundamental na história, pois é aquele que auxilia o menino a conseguir uma bolsa e prosseguir seus estudos. Camus escreve essa carta um dia depois de ganhar o prêmio Nobel: "Sans vous, sans cette main affectueuse que vous avez tendue au petit enfant pauvre que j'étais, sans votre enseignement, et votre exemple, rien de tout cela ne serait arrivé”(CAMUS, 2008a, p. 371).

Ao longo da história, principalmente para aqueles leitores que conhecem um pouco da biografia de Camus, as relações vão ficando cada vez mais estreitas. Assim como Camus, Jacques Cormery nasce em 1913: “C'était une nuit de l'automne 1913” (CAMUS, 2008a, p. 17) e perde seu pai na guerra quando tem apenas 1 ano de idade: "Cormery Henri, dit-il, blessé mortellement à la bataille de la Marne, mort à Saint-Brieuc le 11 octobre 1914" (CAMUS, 2008a, p. 32). Ambos moravam na rua de Lyon, no bairro popular de Belcourt em Alger.

As relações se tornam ainda mais claras quando retornamos a algumas obras de Camus. Em L'Étranger (CAMUS, 1942) o personagem principal mora como Camus e Cormery na rua de Lyon e outros personagens levam sobrenomes da família de Camus: Raymond Sintès, o colega de Meursault, sustenta o sobrenome de solteira de sua mãe e Marie Cardona, a amante de Meursault, leva o sobrenome de solteira de sua avó. Além dos sobrenomes de família, ainda aparecem os dos vizinhos dos Cormery: o personagem Masson de L'Étranger ganha o mesmo nome dos Massons de Le Premier Homme. O tio de Jacques, Ernest, também guarda muitas semelhanças com Salamano e seu cachorro. Em uma nota de 1940 encontramos nos Carnets uma lista de personagens entre os quais aparece "Le vieux et son chien. Huit ans de haine" (CAMUS, 1962, p. 200) onde podemos identificar o velho Salamano de L'Étranger e seu cão. Mais tarde essa relação entre um homem e seu cão também aparecerá com o tio de Jacques: "Ernest et son chien étaient inséparables, et leur entente était parfaite" (CAMUS, 2008a, p. 119). Em 1938, também encontramos sob a denominação de "Personagens", a descrição de algumas características que serão aproveitadas para o tio Cormery: 


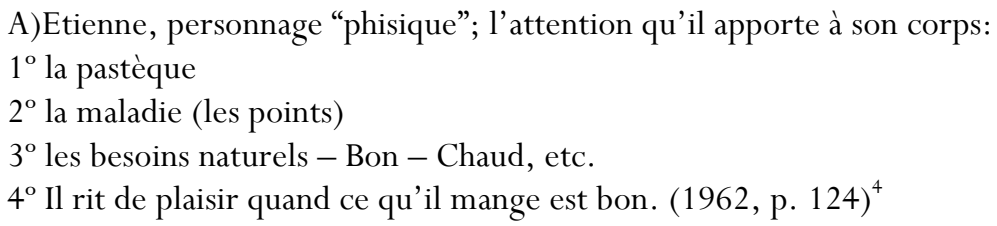

O personagem do tio Ernest, assim como Meursault, era um homem que falava pouco e dispunha apenas de uma centena de palavras; os dois também se configuravam como personagens "físicos”, ou seja, ligados a um mundo sensual: "Sa force et sa vitalité, qui ne pouvaient s'exprimer en discours ni dans les rapports compliqués de la vie sociale, explosaient dans sa vie physique et dans la sensation ${ }^{5}$.

O tio teve um papel fundamental na vida do menino. Ele o amava e se orgulhava dele, levava-o quando pequeno para tomar banho de mar e para caçar, e em certa medida substituiu seu pai durante a infância. A lembrança desse pai desconhecido e ausente é evocada principalmente a partir de uma história contada pela avó: ele fora ver uma execução capital e voltando vomitara várias vezes. O fato impressiona Jacques quando menino, e o persegue durante toda a sua vida em sonhos: às vezes sonhava com a história detalhada do assassinato que aquele condenado cometera, outras vezes sonhava que vinham buscá-lo para ser executado. Como explica Jacques, a angústia que havia perturbado seu pai durante muitos anos fora legada a ele como a única herança evidente e certa de seu pai.

Mais uma vez, a aproximação entre Cormery e Meursault pode ser feita: o protagonista de L'Étranger também não tem pai, e na prisão, após ter sido condenado à morte se lembra da única história que sua mãe lhe contara sobre ele. Isso era tudo de preciso que ele sabia sobre esse homem: ele fora ver a execução de um assassino e retornando vomitara durante toda a manhã. Aos olhos de Meursault, isso era um signo de fraqueza, mas estando ele agora na mesma situação compreendera que não existia nada mais importante na vida de um homem do que ver uma execução capital: se saísse da cadeia, iria assistir a todas. Ambas as narrativas retomam um tema caro na obra de Camus: a pena capital, que ele desenvolve principalmente em Réflexions sur la guillotine (1957).

Os textos de juventude ${ }^{5}$ de Camus, escritos de 1932 a 1938, também retomam referências de sua vida. Neles encontramos histórias sobre uma mãe silenciosa, um tio quase surdo, uma avó dominadora e um pai morto na guerra, do qual apenas se conserva um pequeno estilhaço da bomba que o atingira. Essa família muito se assemelha à de Jacques Cormery.

A primeira tentativa de romance que Camus empreende se alimenta em muito de suas experiências de vida, como ressalta Quilliot (1970) sobre La Mort Heureuse (1971). A narrativa explora as lembranças do bairro pobre onde Camus passou a infância, Belcourt, de seu emprego como despachante marítimo, de sua viagem a Europa Central no verão de 1936 e de suas passagens pela Itália em 1936 e 1937 que também são retomadas nos ensaios de Noces (2008b). A referência mais importante de todas é

\footnotetext{
${ }^{4}$ Podemos ver o desenvolvimento de todos esses pontos no capítulo "Etienne" dedicado ao tio de Cormery, em Le Premier Homme (CAMUS, 2008a, p. 115-116).

${ }^{5}$ Cf. Paul Viallaneix Le Premier Camus suivi de Écrits de jeunesse d'Albert Camus assim como os ensaios de juventude de Camus, L'Envers et l'Endroit.
} 
a tuberculose, doença que acomete Camus por volta de 1930 e da qual Patrice Mersault também sofre, e que por fim acaba morrendo. No entanto, nesse caso, diversos críticos veem um problema na elaboração desta narrativa exatamente no que ela guarda de referências autobiográficas. A coordenação dessas experiências no texto acaba por não se tornar coerente, e esse realismo torna-se artificial. Para Quilliot, essa obra é bem escrita, porém mal alinhavada. Camus com certeza o percebeu, e em 1938 podemos ler em seus Carnets (1962): “Récrire roman”; trata-se possivelmente da passagem para L'étranger.

\section{A criação: este mundo de miséria e sol}

Apoiando-se nessa leitura poderíamos então afirmar que Le Premier Homme seria a autobiografia de Albert Camus: mais que isso, que toda a obra de Camus seria autobiográfica. No entanto, a contradição ainda permanece: o último texto do escritor é um romance e todas as obras que citamos são de natureza ficcional. Agnes Spiquel desenvolve essa questão:

Le Premier Homme a toute la saveur d'une merveilleuse autobiographie: sensations, affects, visages, lieux, atmosphères sont rendus dans une immédiateté extraordinaire; les jeux éperdus sur la plage ou dans le vent, la présence tutélaire d'un vieil instituteur, la sévérité de la grand-mère, la complicité avec l'oncle chasseur, l'austérité de la vie chez les pauvres, la tendresse silencieuse de la mère, les terreurs de l'enfant, ses désespoirs et ses joies, tout cela est rendu avec la vibration du vécu, au point que quantité de gens se sont retrouvés dans cet enfant, même s'ils n'ont pas été pieds-noirs, pauvres, orphelins ou bons élèves. Mais Camus, quoi qu'on en dise, n'a pas voulu écrire son autobiographie. Il parle toujours de son "roman" $[\ldots]$ (SPIQUEL, 2008) $^{6}$

A narrativa tem então todo o sabor de uma autobiografia, uma maravilhosa autobiografia, visto que se concentra principalmente na infância do personagem, com o qual os leitores podem também se identificar. Porém, não se trata de uma autobiografia, mas do que Spiquel chamou de transformação do real em ficção, procedimento que vimos sucintamente em algumas obras de Camus e que seria levado ao limite em Le Premier Homme.

Jacqueline Lévi-Valensi, uma das maiores especialistas na obra de Albert Camus, assinala que a relação que o escritor estabelece com o real, principalmente com sua experiência pessoal, alimenta toda a sua obra: “c'est à dire qu'il ne conçoit alors le roman que comme expression du réel” (1982, p. 169). Para ela, esse procedimento do processo de criação camusiano responderia ao mesmo tempo a exigências estéticas e morais: como permanecer fiel a um mundo que se abandona? Como permanecer fiel a esse mundo da infância, pobre e iluminado, quando o adulto conhece uma carreira de sucesso como escritor fora da Argélia?

A mauvaise conscience, aveu nécessaire. L'œuvre est un aveu, il me faut témoigner. Je n'ai qu'une chose à dire, à bien voir. C'est dans cette vie de pauvreté, parmi ces gens humbles ou vaniteux, que j'ai le plus sûrement touché ce qui me paraît le sens vrai de la vie. Les ouvres d'art n'y suffiront jamais. L'art n'est pas tout pour moi. Que du moins ce soit un moyen (CAMUS, 1962, p. 16).

\footnotetext{
${ }^{6}$ SPIQUEL, Agnes Disponível em: <http://www.etudes-camusiennes.fr/dotclear/index.php?2008/12/30/17-le-premier-homme>
} 
É somente através da obra de arte, mais especificamente através da literatura, que Camus pretende ser fiel a esse mundo. A nota acima data de 1935; em 1938 encontramos nos Carnets uma reflexão mais elaborada acerca dessa estética:

Artiste et œuvre d'art. La véritable œuvre d'art est celle qui dit moins. Il y a un certain rapport entre l'expérience globale d'un artiste, sa pensée + sa vie (son système en un sens - omission faite de ce que le mot implique de systématique), et l'œuvre qui reflète cette expérience. Ce rapport est mauvais lorsque l'œuvre d'art donne toute l'expérience entourée d'une frange de littérature. Ce rapport est bon lorsque l'œuvre d'art est une part taillé dans l'expérience, facette de diamant où l'éclat intérieur se résume sans se limiter. Dans le premier cas, il y a surcharge et littérature. Dans le second, œuvre féconde à cause de tout un sous-entendu d'expérience dont on divine la richesse. Le problème est d'acquérir ce savoir-vivre (avoir vécu plutôt) qui dépasse le savoir-écrire. Et dans la fin, le grand artiste est avant tout un grand vivant (étant compris que vivre, ici, c'est aussi penser sur la vie — c'est même ce rapport subtil entre l'expérience et la conscience qu'on en prend.) (CAMUS, 1962, p. 127)

Reencontraremos esta anotação em Le Mythe de Sisyphe inserida numa reflexão sobre a criação absurda: “On peut voir là en même temps une règle d'esthétique. La véritable œuvre d'art est toujours à la mesure humaine” (CAMUS, 1942, p. 134). Essa passa a ser uma regra da poética do autor: a ligação entre a experiência do vivido e a obra, porém, mais do que fatos essas experiências devem trazer uma consciência. Da reflexão sobre o vivido deve nascer um sentido, uma verdade.

Quando Camus ainda jovem ensaia seus primeiros textos, ele o faz distante das imagens desse mundo da infância. A primeira ideia que Camus elaborou sobre a arte foi a da evasão. Segundo Viallaneix (1973, p. 21), nos exercícios literários do adolescente há uma palavra que aparece frequentemente, lassitude: "Ces rêveries sont nées de grandes lassitudes" (CAMUS, 1973, p. 177).

As primeiras experiências de leituras de Camus, assim como as de Cormery, também o afastam do mundo em que vivia para um mundo de sonhos. Ele encontra nos manuais da escola primária (elaborados para as crianças da metrópole), um mundo exótico, onde "crianças de gorro e echarpe de lã, com os pés calçados de tamancos, voltavam para casa no frio gelado levando feixes de lenha por caminhos cobertos de neve" (CAMUS, 1994, p. 130). Assim, o menino se afasta cada vez mais dos seus à medida que mergulha nos livros, ele descobre o divórcio que afasta a literatura da vida ${ }^{7}$. Sua estética se configura nesse momento como uma negação do real, é o que demonstram textos de 1932 como "Essai sur la musique" e "Intuitions",

Pour nous, l'art ne sera ni l'expression du Réel, ni l'expression d'un Réel embelli jusqu'à être falsifié. Ce sera simplement l'expression de l'idéal. Ce sera la création d'un monde de Rêve, assez séduisant pour nous cacher le monde où nous vivons et toutes ses horreurs (CAMUS, 1973, p. 150-151).

\footnotetext{
${ }^{7}$ Assim como Cormery: "De tout temps Jacques avait dévoré les livres qui lui tombaient sous la main et les avalait avec la même avidité qu'il mettait à vivre, à jouer et à rêver. Mais la lecture lui permettait de s'échapper dans un univers innocent où la richesse et la pauvreté étaient également intéressants parce que parfaitement irréelles" (CAMUS, 2008, p. 266).
} 
Porém uma experiência de leitura será fundamental para uma mudança de estética, que veremos pouco a pouco manifestar-se nos textos seguintes. Em 1931, durante seu segundo ano de filosofia, seu professor Jean Grenier empresta-lhe um livro. Trata-se de La Douleur de André de Richaud:

[...] je n'ai jamais oublié son beau livre, qui fut le premier à me parler de ce que je connaissais: une mère, la pauvreté, de beaux soirs dans le ciel. Il dénouait au fond de moi un nœud de liens obscurs, me délivrait d'entraves dont je sentais la gêne sans pouvoir les nommer. [...] Je venais d'apprendre que les livres ne versaient pas seulement l'oubli et la distraction. Mes silences têtus, ces souffrances vagues et souveraines, le monde singulier qui m'entourait, la noblesse des miens, leur misère, mes secrets enfin, tout cela pouvait donc se dire! Il y avait une délivrance, une ordre de vérité, où la pauvreté, par exemple, prenait tout d'un coup son vrai visage, celui que je soupçonnais et révérais obscurément. La Douleur me fit entrevoir le monde de la création (CAMUS, 1981, p. 1117-1118).

Através desse livro, o jovem Camus aprende uma lição valiosa, uma lição libertadora: os livros não somente tratavam de uma realidade distante, mas toda sua existência poderia ser matéria de criação. O real, o vivido passa a ser matéria de criação, mas não se trata aqui de realismo, mas de erigir o que Lévi-Valensi (2006, p. 533) chamou de uma mitologia do real, uma mitologia dos dramas humanos.

É a partir dessta nova estética que Camus começa a escrever, como fica evidenciado a partir da publicação de seu primeiro livro L'envers et l'endroit, e que encontrará seu ápice em Le Premier Homme, o último.

O mundo de pobreza e luz onde Camus vivera tornara-se sua matéria de criação, Camus afirma isso em prefácio de 1958 para a reedição de L'envers et l'endroit, dois anos antes de sua morte. É exatamente no momento dessa reflexão que o escritor está redigindo Le Premier Homme, ou seja, o escritor conclui nesse momento que toda a sua obra gira em torno destas imagens, ou seja, do vivido, do real ${ }^{8}$.

Assim vemos que Camus identifica L'Envers et l'Endroit como o ponto de partida para tudo o que ele escreve em seguida, e esse ponto se encontra no real, na infância, "dans ce monde de pauvreté et de lumière où [il a] longtemps vécu." (CAMUS, 2007, p. 13) No entanto, podemos observar que bem antes da publicação de seu primeiro livro em 1937, Camus começa a esboçar textos que tem esse real como ponto de partida.

Graças à publicação dos escritos de juventude de Camus podemos ter acesso aos textos de "Les voix du quartier pauvre" datados de 1934 e que pertenciam a sua primeira mulher, Simoné Hié. Nesses textos, encontramos como personagens centrais a figura de dois idosos: uma mulher "la femme qui ne pensait pas" e um homem "l'homme qui était né pour mourir". Ainda temos mais dois textos: "la voix qui était soulevée par de la musique" e "la femme malade qu'on abandonnait pour aller au cinéma", cujo personagem podemos facilmente ligar à senhora do primeiro texto. Aqui vemos já aparecerem temas caros a Camus: a reflexão sobre a velhice, a doença e a morte, que serão centrais para o desenvolvimento de suas primeiras narrativas como La Mort Heureuse e L'Étranger.

\footnotetext{
8 “'Au contraire, relisant L'Envers et l'Endroit après tant d'années, pour cette édition, je sais instinctivement devant certaines pages, et malgré les maladresses, que c'est cela. Cela, c'est-à-dire cette vieille femme, une mère silencieuse, la pauvreté, la lumière sur les oliviers d'Italie, l'amour solitaire et peuplé, tout ce qui témoigne, à mes yeux, de la vérité" (CAMUS, 2007, p. 25).
} 


\section{Os pobres não têm memória}

Sendo assim, o que nos interessa ressaltar a respeito dos textos de "Les voix du quariter pauvre" é o papel dado à lembrança. Para aceder a ela, o narrador se refere a um momento quase proustiano: "Et pour recréer tout cet amour nous n'avons qu'un détail, mais qui suffit: une odeur de chambre trop longtemps fermée, le son particulier d'un pas sur la route” (CAMUS, 1973, p. 271).

Em toda a obra de Camus os cheiros ocuparão um lugar fundamental, fruto de uma relação sensual com o mundo. Em Le Premier Homme eles aparecerão ligados às lembranças:

Quand il arriva devant la porte, sa mère l'ouvrait et se jetait dans se bras. [...] et il la sentait contre ses bras les côtes, les os durs et saillants des épaules un peu tremblantes, tandis qu'il respirait la douce odeur de sa peau qui lui rappelait cet endroit, sous la pomme d'Adam, entre les deux tendons jugulaires, qu'il n’osait plus embrasser chez elle, mais qu'il aimait respirer et caresser étant enfant et les rares fois où elle le prenait sur ses genoux et où il faisait semblant de s'endormir, le nez dans ce petit creux qui avait pour lui l'odeur, trop rare dans sa vie d'enfant, de la tendresse (CAMUS, 2008a, p. 68).

Em ambos os textos a relação com o real, com esse mundo da infância, é mediado pelas lembranças do homem adulto.

É então que aparece a figura da mãe "Il avait eu une mère" (CAMUS, 1973, p. 273), uma mulher doente e que não pensava direito, que tinha uma mãe rude e dominadora. Uma vez emancipada pelo casamento, retorna para a casa da mãe logo que o marido morre. Ele morrera no campo de batalha, o hospital enviara à viúva o pequeno estilhaço da bomba que o atingira. Para sustentar seus filhos, ela trabalha como faxineira e deixa a educação deles aos cuidados da avó. O filho mais novo ama sua mãe, mas não ousa dizê-lo; a mãe por sua vez conserva-se “dans ces silences”, em sua indiferença, “elle ne l'a jamais caressé puisqu'elle ne saurait pas” (CAMUS, 1973, p. 274).

Esse mesmo texto de "Les voix du quartier pauvre" será recuperado em L'envers et l'endroit. No texto "L’ironie", teremos a descrição dessa avó rude e em "Entre oui et non" a descrição da relação com a mãe. O segundo texto inicia-se também com a evocação da lembrança: "S'il est vrai que les seuls paradis sont ceux qu'on a perdus, je sais comment nommer ce quelque chose de tendre et d'inhumain qui m'habite aujourd'hui" (CAMUS, 2007, p. 55). Podemos perceber que existe uma intercambialidade entre esses escritos: a anedota de "Les voix du quartier pauvre" é recuperada e expandida em "Entre oui et non”, e será recuperada em Le Premier Homme.

Dessa forma, observamos que além da transformação do real em ficção, o processo de criação de Camus também se faz por um aproveitamento de textos anteriores, como explica Lévi-Valensi: “On voit comment Camus gère le capital de phrases, d'idées, d'expressions, qu'il se constitue peu à peu pendant ces années où l'œuvre s'élabore” (2006, p. 231).

Entre 1934 e a redação de Le Premier Homme se interpõe o esboço de um romance. Ele foi recuperado pela pesquisa de Lévi-Valensi em 1981 e recebeu o nome de seu personagem principal: "Louis Raingeard". Esse romance recupera as mesmas lembranças da infância de Camus e passagens de "Les voix du quartier pauvre", mas que agora retiram sua unidade de um personagem principal. O 
romance permanece inacabado, e Camus nunca faz nenhuma alusão a ele. No entanto, é a expressão de uma ambição criadora que se inicia em "Les voix": a relação com o real se faz da mesma maneira, o tratamento da matéria também, a realidade que ele toma como ponto de partida é estritamente a mesma: os personagens da saga familiar e para-familiar.

Dessa forma, vemos que a obra romanesca de Camus começa e acaba em fragmentos de um romance autobiográfico. É interessante notar esse fato, pois o escritor não costumava nomear seus textos como romances, mas como narrativas ou crônicas. Essa denominação aparecerá, como vimos, apenas para designar Le Premier Homme, e podemos ver que o romanesco para Camus estava ligado ao autobiográfico, ou melhor formulando: ao aproveitamento da matéria do real.

Ao contrário, em 1950, Camus faz notar o quanto os personagens de suas narrativas não têm relação com o real (embora essa narrativa contenha elementos retirados do real):

Mon oeuvre pendant ces deux premiers cycles: des êtres sans mensonges, donc non réels. Ils ne sont pas au monde. C'est pourquoi sans doute et jusqu'ici je ne suis pas un romancier au sens où l'entend. Mais plutôt un artiste qui crée des mythes à la mesure de sa passion et de son angoisse (CAMUS, 1963, p. 325).

Através de Le Premier Homme, mais que escrever uma autobiografia, Camus pretendia erigir uma mitologia do real, engendrar uma memória para aqueles que não possuíam ao menos uma história.

Em todos os textos que analisamos até agora podemos notar que a figura central ligada à infância é a da mãe, seus silêncios e seu indiferente amor, o pai será sempre uma figura ausente. Mas no ano de 1951 encontramos uma nota para Le Premier Homme que será central para o desenrolar da narrativa: "À 35 ans le fils va sur la tombe de son père et s'aperçoit que celui-ci est mort à 30 ans. Il est devenu l'aîné" (CAMUS, 1989, p. 27-28). A história, então, passará a se centrar na busca desse pai desconhecido "recherche d'un père ou le père inconnu", como sustenta uma nota de 1953, ou seja, a busca de uma origem, de uma filiação.

Jacques constata essa necessidade quando ainda criança: ele e seu colega Pierre conhecem Didier, e com ele aprendem o que significava uma família francesa média. A importância da filiação é exaltada por Didier, através das histórias de seus avós e bisavós, que lhe forneciam exemplos para a conduta de todos os dias: "mon grand-père disait que... papa veut que", ao contrário de Jacques e de todos os outros órfãos da guerra, árabes ou franceses, filhos e filhas sem pai que deveriam aprender a viver "sans leçon et sans héritage" (CAMUS, 2008, p. 83). A família de Didier possuía uma casa na França, país que ele chamava de "notre patrie", e para a qual ele retornava nas férias. Diferentemente de Didier, Jacques e Pierre:

[...] quoique à moindre degré, se sentait d'une autre espèce, sans passé, ni maison de famille, ni grenier bourré de lettres et photos, citoyens théoriques d'une nation imprécise où la neige couvrait les toits alors qu'eux-mêmes grandissaient sous un soleil fixe et sauvage [...] (CAMUS, 2008a, p. 227).

A única lembrança guardada na casa de Jacques é o estilhaço da bomba que o atingira seu pai:

L'éclat d'obus qui avait ouvert la tête de son père était dans une petite boîte de biscuits derrière les mêmes serviettes de la même armoire, avec les cartes écrites du front et qu'il pouvait réciter par cœur dans leur sécheresse et leur brièveté. "Ma 
chère Lucie. Je vais bien. Nous changeons de cantonnement demain. Fais bien attention aux enfants. Je t'embrasse. Ton mari” (CAMUS, 2008a, p. 76).

O que se conservara desse pai é apenas um pedaço do que fora sua morte e não sua vida, e as cartas que ele envia são decoradas pelo menino em razão de sua brevidade. Jacques não pode recuperar essa história visto que seus traços não foram conservados, ou quando existem são insuficientes e breves como as cartas de seu pai: lembranças de uma família analfabeta, de uma mãe um pouco surda e que possuía um vocabulário restrito.

Além disso, Jacques é inserido em uma história que não é a dele nem a de seus pais. Na escola não lhe ensinam a história da Argélia, mas a história da França, essa nação imprecisa, "la patrie”, palavra vazia de sentido para a sua mãe. Ao contrário, Jacques havia sido criado sob esse sol argelino: "oui, il avait vécu ainsi dans les jeux de la mer, du vent, de la rue, sous le poids de l'été et les lourdes pluies du bref hiver, sans père, sans tradition transmise [...]" (CAMUS, 2008a, p. 300).

Como então relatar essa história? Como Albert Camus, que crescera sob esse mesmo sol e essa mesma miséria, poderia escrever uma autobiografia, já que ela se alimenta de lembranças?

Jacques sai em busca dessas lembranças, mas através dessa busca, das perguntas com as quais interpela sua mãe sobre seu passado e a história de seu pai, Cormery faz uma descoberta impressionante: os pobres não têm memória.

La mémoire des pauvres déjà est moins nourrie que celle des riches, elle a moins de repères dans l'espace puisqu'ils quittent rarement le lieu où ils vivent, moins de repères aussi dans le temps d'une vie uniforme et grise. Bien sûr, il y a la mémoire du cœur dont on dit qu'elle est la plus sûre, mais le cœur s'use à la peine et au travail, il oublie plus vite sous le poids des fatigues. Le temps perdu ne se retrouve que chez le riches. Pour les pauvres, il marque seulement les traces vagues du chemin de la mort. Et puis, pour bien supporter, il ne faut pas trop se souvenir [...] (CAMUS, 2008a, p. 93).

Mais que isso, além de não terem memória, os pobres não são ao menos lembrados, nascem e morrem como desconhecidos:

À vrai dire, il n'avait pas été aidé. Une famille où l'on parlait peu, où on ne lisait ni n'écrivait, une mère malheureuse et distraite, qui l'aurait renseigné sur ce jeune et pitoyable père? Personne ne l'avait connu que sa mère qui l'avait oublié. Il en était sûr. Et il était mort inconnu sur cette terre où il était passé fugitivement, comme un inconnu (CAMUS, 2008a, p. 36).

Assim, podemos nos perguntar se esse não seria o motivo pelo qual Albert Camus escreverá esse romance: engendrar uma memória inexistente, ou seja, somente possível através da ficção. Como ressalta Buffard-Morel (1999, p. 58), a palavra "imaginar" é muito mais evocada no romance do que a palavra "lembrar". O próprio narrador constata essa dificuldade em saber se suas lembranças são verdadeiras: "il n'était pas sûr que ces souvenirs si riches, si jaillissants en lui, fussent vraiment fidèles à l'enfant qu'il avait été" (CAMUS, 2008a, p. 149). De fato, mesmo em um texto explicitamente autobiográfico, podemos duvidar do papel da memória e pensar que a imaginação tem também aí um papel importante. 
É somente através da ficção que o autor pode criar uma narrativa de filiação, narrando seu nascimento ao qual confere uma dimensão mítica, cena que nos leva a pensar em uma natividade quase bíblica. Como explica Chabot (1999, p. 67), o primeiro capítulo de Le Premier Homme não se deve ao papel da memória nem da história, pois é escrito em forma de mito e eles são a memória humana antes da história. A narrativa mítica relata como nasceram os heróis e também narra a origem dos povos, mas o que dizer de uma terra colonizada, onde se misturaram culturas, línguas e histórias? Como Jacques, os traços da história argelina também foram apagados.

A história desse povo será aos poucos recuperada com a história de Jacques. Tudo se inicia quando ele retorna à Argélia já adulto: "Mais il s'était évadé, il respirait, [...] il pouvait enfin dormir et revenir à l'enfance dont il n'avait jamais guéri, à ce secret de lumière, de pauvreté chaleureuse qui l'avait aidé à vivre et à tout vaincre (CAMUS, 2008a, p. 53).

A infância se configura assim como a chave de toda a sua vida, como a força que o ajudou a viver e tudo superar. É o que Camus no prefácio de 1958, ele fora colocado a meio caminho da miséria e do sol, dessa forma, "la belle chaleur qui regnait sur mon enfance m'a privé de tout ressentiment" (CAMUS, 2007, p. 14). Da mesma forma encontramos Cormery, cujo extrema pobreza da infância não impediu que ela fosse feliz, crescendo nas ruas de Argel sob a proteção das divindades indiferentes do sol e do mar (CAMUS, 2008a, p. 227).

Essa infância aparece com uma aura edênica, é um paraíso perdido que só pode ser recuperado através da literatura. A infância é a fonte da literatura e ela é por sua vez o único meio para retornar a ela.

Para Camus, todo o sentido da vida nasce dessa infância pobre em meio a pessoas humildes e analfabetas, a literatura será então um meio de expressar essa verdade apreendida durante a infância: "Par son seul silence, sa reserve, sa fierté naturelle et sobre, cette famille, qui ne savait même pas lire, m’a donné alors mes plus hautes leçons, qui durent toujours" (CAMUS, 2008a, p. 15).

Dessa forma, podemos observar que na obra de Camus não são somente as tensões entre o autobiográfico e o ficcional que estão em questão, mas o retorno a essa infância pobre e iluminada, ponto de partida, como vimos, de tudo que ele escreve. Podemos então afirmar que através de Le Premier Homme e de todos os textos iniciais, Camus desejasse, por meio da literatura, oferecer uma voz àqueles que não a possuíam, dar uma memória aos pobres, a sua família e ao seu país.

"En somme, je vais parler de ceux que j'aimais"

Albert Camus 


\section{Referências bibliográficas}

\section{Obras de Albert Camus}

CAMUS, Albert. Carnets I. Mai 1935 - Février1942. Paris: NRF/Gallimard, 1962. Carnets II. Janvier 1942 - Mars 1951. Paris: NRF/Gallimard, 1965. . Carnets III. Mars 1951 - Décembre 1959. Paris: NRF/Gallimard, 1989. . Essais. Paris: NRF/Gallimard, Bibliothèque de la Pléiade, 1981. . La mort heureuse In: Cahiers Albert Camus I, Paris: Gallimard, 1971. . Le mythe de Sisyphe : essai sur l'absurde. Paris: Gallimard Paris: Gallimard, [1942] 2008c. . L'envers et l'endroit. Paris: Gallimard, [1958] 2007. . L'étranger Paris: Gallimard, [1942] 1996. . Noces. Paris: Gallimard, [1938] 2008b. "Réflexions sur la guillotine". In: KOESTLER, Arthur ; BLOCH-MICHEL, Jean. Réflexions sur la Peine Capitale. Paris: Calmann-Lévy,1957. O Primeiro Homem. Rio de Janeiro: Nova Fronteira, 1994. . Le Premier Homme. Paris: Gallimard, 2008. . Théâtre, Récits, Nouvelles. Bibliothèque de la Pléiade. Paris: NRF/Gallimard, 1981.

\section{Obras sobre Albert Camus}

BUFFART-MOREL, Brigitte. "La mémoire du cœur: approche stylistique du Premier Homme d'Albert Camus". Roman 20-50, n 27, junho 1999.

CHABOT. "La mémoire des pauvres". Roman 200-50, n²7, junho 1999.

GRENIER, Roger. Albert Camus, soleil et ombre: une biographie intellectuelle. Paris: Gallimard, 1999.

. "Les Carnets: des notes de travail au journal intime". In: Magazine Littéraire, n. 276, p.18-53, abril 1990.

LÉVI-VALENSI. Albert Camus ou la naissance d'un romancier Paris: Gallimard, 2006.

; GAY-CROSIER, R. “Albert Camus: œuvre fermée, œuvre ouverte?". In: Cahiers Albert Camus V. Paris: Gallimard, 1982.

QUILLIOT, Roger. La mer et les prisons: essais sur Albert Camus. Viena: Gallimard, 1970.

TODD, Olivier. Albert Camus: une vie. Paris: Gallimard, 1999.

VIALlANEIX, Paul. Le premier Camus Suivi de Écrits de Jeunesse d'Albert Camus In: Cahiers Albert Camus II. Paris: Gallimard, 1973.

“Albert Camus n'est plus" La Liberté 5 de janeiro de 1960. Disponível em: <http://www.cheny.net/plus/villeblevin01_02.html> Acesso em: 12 nov. 2009.

Artigo recebido em: 18/01/2010

Artigo aprovado em: 20/02/2010

Referência eletrônica: GESKE, Samara Fernanda Almeida Oliveira de Lócio e Silva. Este mundo de miséria e sol: a narrativa autobiográfica e a relação com o real na obra de Albert Camus, Revista Criação \& Crítica, n. 4, p. 159-170, 2010. Disponível em:

<http://www.fflch.usp.br/dlm/criacaoecritica/dmdocuments/13CC_N4_SGeske.pdf> 